\title{
The efficacy and safety of Ginkgo biloba extract as an adjuvant in type 2 diabetes mellitus patients ineffectively managed with metformin: a double- blind, randomized, placebo-controlled trial
}

This article was published in the following Dove Press journal:

Drug Design, Development and Therapy

\begin{abstract}
Tavga Ahmed Aziz'
Saad Abdulrahman Hussain ${ }^{2}$

Taha Othman Mahwi ${ }^{3}$

Zheen Aorahman Ahmed'

Heshu Sulaiman Rahman ${ }^{4-6}$

Abdullah Rasedee ${ }^{6}$

'Department of Pharmacology and Toxicology, College of Pharmacy,

University of Sulaimani, Sulaimani

City, ${ }^{2}$ Department of Pharmacology and Toxicology, Faculty of Pharmacy, Al-Rafidain University, Baghdad, ${ }^{3}$ Department of Medicine, College of Medicine, ${ }^{4}$ Department of Clinic and Internal Medicine, College of Veterinary Medicine, University of Sulaimani, ${ }^{5}$ Department of Medical Laboratory Sciences, College of Health Sciences, Komar University of Science and Technology, ChaqChaq-Qularaisi, Sulaimani City, Iraq; ${ }^{6}$ Department of Veterinary Laboratory Diagnosis, Faculty of Veterinary Medicine, Universiti Putra Malaysia, Selangor, Malaysia
\end{abstract}

Correspondence: Saad Abdulrahman Hussain

Department of Pharmacology and Toxicology, Faculty of Pharmacy, Al-Rafidain University College, 10052

Al-Mustansiriya, Baghdad, Iraq

Tel +96 47901712624

Email saad.hussain@coalrafidain.edu.iq

Abdullah Rasedee

Department of Veterinary Laboratory

Diagnosis, Faculty of Veterinary Medicine,

Universiti Putra Malaysia, 43300 UPM

Serdang, Selangor, Malaysia

Tel +60 I2 372 I294

Email rasedee@gmail.com
Background and aim: Type 2 diabetes mellitus (T2DM) is one of the major diseases confronting the health care systems. In diabetes mellitus (DM), combined use of oral hypoglycemic medications has been shown to be more effective than metformin (Met) alone in glycemic control. This study determined the effects of Ginkgo biloba (GKB) extract as an adjuvant to Met in patients with uncontrolled T2DM.

Subjects and methods: Sixty T2DM patients were recruited in a randomized, placebocontrolled, double-blinded, and multicenter trial. The patients, currently using Met, were randomly grouped into those treated with either GKB extract $(120 \mathrm{mg} /$ day) or placebo (starch, $120 \mathrm{mg}$ /day) for 90 days. Blood glycated hemoglobin (HbA1c), fasting serum glucose, serum insulin, body mass index (BMI), waist circumference (WC), insulin resistance, and visceral adiposity index (VAI) were determined before (baseline) and after 90 days of GKB extract treatment.

Results: GKB extract significantly decreased blood $\mathrm{HbA} 1 \mathrm{c}(7.7 \% \pm 1.2 \%$ vs baseline $8.6 \% \pm 1.6 \%, P<0.001)$, fasting serum glucose $(154.7 \pm 36.1 \mathrm{mg} / \mathrm{dL}$ vs baseline $194.4 \pm 66.1 \mathrm{mg} / \mathrm{dL}$, $P<0.001)$ and insulin $(13.4 \pm 7.8 \mu \mathrm{U} / \mathrm{mL}$ vs baseline $18.5 \pm 8.9 \mu \mathrm{U} / \mathrm{mL}, P=0.006)$ levels, BMI $\left(31.6 \pm 5.1 \mathrm{~kg} / \mathrm{m}^{2}\right.$ vs baseline $\left.34.0 \pm 6.0 \mathrm{~kg} / \mathrm{m}^{2}, P<0.001\right)$, waist WC $(102.6 \pm 10.5 \mathrm{~cm}$ vs baseline $106.0 \pm 10.9 \mathrm{~cm}, P<0.001)$, and VAI (158.9 \pm 67.2 vs baseline 192.0 $\pm 86.2, P=0.007)$. GKB extract did not negatively impact the liver, kidney, or hematopoietic functions.

Conclusion: GKB extract as an adjuvant was effective in improving Met treatment outcomes in T2DM patients. Thus, it is suggested that GKB extract is an effective dietary supplement for the control of DM in humans.

Keywords: T2DM, Ginkgo biloba extract, metformin, BMI, glycemic control, insulin resistance

\section{Introduction}

Diabetes mellitus (DM) is a metabolic disorder that poses major health care challenges. The disease is characterized by chronic hyperglycemia and aberrant carbohydrate, fat, and protein metabolism as a result of inadequate secretion and/or action of insulin. ${ }^{1}$ In DM, genetic and environmental factors are among the causes of insulin resistance (IR) and pancreatic $\beta$-cell dysfunction that leads to impairment in insulin action and/or production. ${ }^{2}$ Type 2 DM (T2DM) is the most common type of DM, comprising $90 \%$ of all diabetic patients. Unfortunately, T2DM patients often develop IR, resulting in failure of the body to efficiently use insulin for tissue metabolism. ${ }^{3}$ 
Many therapeutic agents have been developed to regulate blood glucose homeostasis. These therapeutics have various modes of action, including stimulation of insulin release and sensitivity, such as GLP-1 analogs, and inhibition of DPP-4, such as sodium-glucose cotransporter-2 and $\alpha$-glucosidases. ${ }^{4,5} \mathrm{Current}$ antidiabetic agents are fraught with low efficacy due to some factors including IR and undesirable side effects such as weight gain, hypoglycemia, kidney toxicity, and gastrointestinal disorders including diarrhea, flatulence, sour stomach, belching, nausea, vomiting, and indigestion. ${ }^{6,7}$

In many societies, plant-derived traditional medicines have been the mainstay of human health care. In fact, for diabetes alone, at least 1,200 plants have been claimed to possess properties that could alleviate, if not cure the disease. Medicinal herbs, for example, Ginkgo biloba L. leaf extract (GKB extract), contain various biologically active compounds that could affect insulin action and production. ${ }^{89}$ GKB is believed to be neuroprotective, antioxidative, free radical scavenging, membrane stabilizing, cardioprotective, anti-inflammatory, antiapoptotic, and antiplatelet-activating factor. ${ }^{10,11}$ In addition, the plant products have been used to treat arteriosclerosis, thrombus formation, ischemic heart disease, hypertension, and more recently for the prevention of DM. ${ }^{12,13}$

In 2012, the cost of health care associated with diabetes in the USA alone was estimated to be US\$245 billion. ${ }^{14}$ Health care cost will continue to increase; therefore, there is an urgent need for cheaper alternative therapies or adjuvant agents. The GKB extract is relatively inexpensive and a potentially effective therapeutic compound for the treatment of uncontrolled diabetes. Thus, this study determined the effect of GKB extract as an adjuvant therapeutic compound to metformin (Met) for the treatment of T2DM.

\section{Subjects and methods Materials}

Met tablets (500 or 850 mg; Merck Santé S.A.S., Lyon City, France) were obtained from a verified and licensed pharmacy. GKB extract as the standard powder (EGb761) was obtained from Apollo Healthcare Resources (West Coast Vista, Singapore). Placebo was specially formulated with $120 \mathrm{mg}$ starch/ capsule (Pioneer Pharmaceutical Company Pharmaceutical Industries, Sulaymaniyah, Iraq).

\section{Patients}

The study was approved by the Ethical Committee of the College of Medicine/University of Sulaimani, Iraq, and performed in accordance with the principles of the Declaration of Helsinki as revised in 2000. Written informed consent was obtained from the participants prior to enrollment in the study. Subjects were free of medications, other than Met, that could influence the blood glucose concentration.

\section{Methods}

\section{Study design and patient treatment}

The study was a randomized, placebo-controlled, doubleblinded, and multicenter clinical trial conducted between December 2016 and October 2017 at the Center of Diabetes and Endocrine Glands, Directory of Health, Sulaimani city, Iraq. Patients were recruited for the study from public hospitals and private clinics according to the predetermined selection criteria. Patients included in the study were of both sexes with age ranging from 25 to 65 years, diagnosed with T2DM for not $<1$ year, and with glycemic status uncontrolled by Met therapy alone. The exclusion criteria included pregnant women; patients with type $1 \mathrm{DM}$, ischemic heart disease, cardiac arrhythmias, glucose-6-phosphate dehydrogenase deficiency, bleeding disorders, and seizures; patients with known hypersensitivity to GKB extract, Met, or placebo; and those taking supplements containing multivitamins or polyphenols.

Sixty of 80 patients who were screened and found to be eligible for the study were randomized into two groups of 30 each (Figure 1) as follows: the placebo group received placebo (120 mg starch/capsule) in addition to their usual Met $(1.24 \pm 0.67 \mathrm{~g} /$ day $)$ dose and the GKB group received GKB extract (120 mg/capsule) in addition to their usual Met $(1.36 \pm 0.45 \mathrm{~g} /$ day) dose (Table 1). Treatments were given orally, once a day for 90 consecutive days. Patient follow-ups were performed monthly to ensure patient safety and compliance. Unfortunately, only 20 patients from the placebo group and 27 from the GKB group completed the experiment and were included in the final data analysis. The most frequent reasons for patients exiting the study were loss of interest and failure to administer regular treatment doses.

\section{Physical tests}

Body weight, waist circumference (WC), and body mass index (BMI) were obtained for each patient before commencement and at the end of the 90-day experiment.

\section{Biochemical and hematological tests}

Blood was taken by venipuncture from $12 \mathrm{~h}$ fasted patients before and after institution of the 90-day GKB extract treatment. Approximately $2.0 \mathrm{~mL}$ of blood was drawn into EDTA tubes for determination of glycated hemoglobin (HbA1c) by colorimetric methods (Roche-Cobas C 311; Roche 


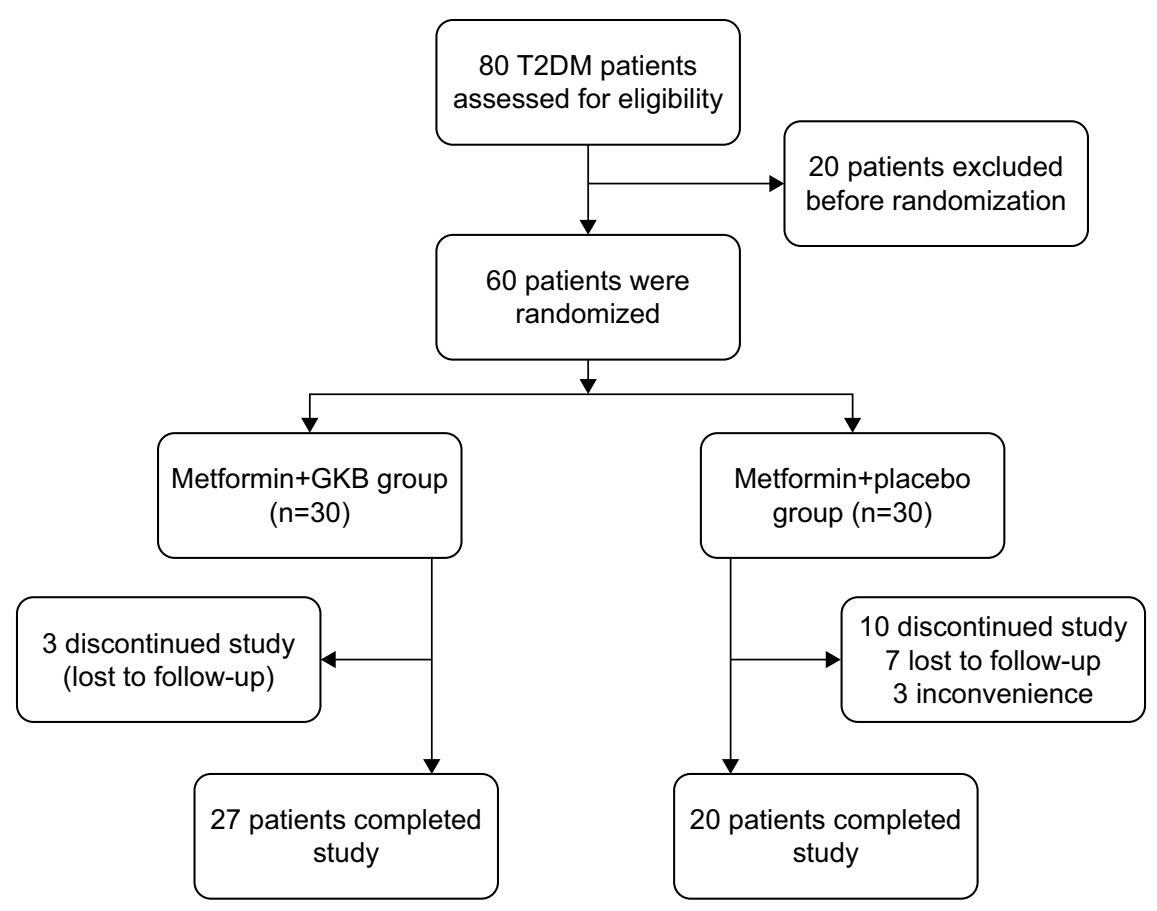

Figure I Flowchart displaying the participants' screening, randomization, and treatment. Abbreviations: GKB, Ginkgo biloba; T2DM, type 2 diabetes mellitus.

Diagnostics GmbH, Mannheim, Germany), hemoglobin ( $\mathrm{Hb})$ concentration, hematocrit, red blood cell, and white blood cell counts using the hematology analyzer (Spincell 3; Spinreact SAU, Girona, Spain). Eight milliliters was drawn into plain tubes and allowed to clot before centrifuging at $300 \times g$ for $20 \mathrm{~min}$ to obtain the serum. The sera were either analyzed

Table I Baseline values of the T2DM patients enrolled in the study

\begin{tabular}{llll}
\hline Parameters & $\begin{array}{l}\text { Met+placebo, } \\
\mathbf{n}=\mathbf{2 0}\end{array}$ & $\begin{array}{l}\text { Met+GKB, } \\
\mathbf{n}=\mathbf{2 7}\end{array}$ & P-value \\
\hline Age (years) & $48.2 \pm 10.3$ & $48.7 \pm 9.6$ & 0.85 \\
Male (\%) & $3(15)$ & $5(17.2)$ & 0.42 \\
Weight $(\mathrm{kg})$ & $83.4 \pm 12.2$ & $82.7 \pm 17$ & 0.88 \\
BMI $\left(\mathrm{kg} / \mathrm{m}^{2}\right)$ & $34.2 \pm 6.2$ & $33.9 \pm 6.0$ & 0.8 \\
WC $(\mathrm{cm})$ & $103.9 \pm 9.7$ & $105.8 \pm 10.9$ & 0.54 \\
VAl & $196.5 \pm 82.8$ & $191.8 \pm 86.2$ & 0.85 \\
Diabetes duration (years) & $2.93 \pm 2.1$ & $3.52 \pm 3.1$ & 0.47 \\
Met therapy & & & \\
Duration of use (months) & $28 \pm 26.2$ & $40.9 \pm 38.4$ & 0.2 \\
Daily dose (g) & $1.24 \pm 0.67$ & $1.36 \pm 0.45$ & 0.45 \\
Laboratory data & & & \\
HbAIc $(\%)$ & $8.8 \pm 2.3$ & $8.6 \pm 1.6$ & 0.69 \\
FSG (mg/dL) & $166.7 \pm 56.8$ & $194.4 \pm 66.1$ & 0.14 \\
Serum insulin $(\mu \mathrm{U} / \mathrm{mL})$ & $17.5 \pm 8.1$ & $18.5 \pm 8.9$ & 0.72 \\
Insulin resistance & $9.4 \pm 7.1$ & $9.0 \pm 5.3$ & 0.83 \\
\hline
\end{tabular}

Note: Values are presented as mean \pm SD.

Abbreviations: BMI, body mass index; FSG, fasting serum glucose; GKB, Ginkgo biloba; HbAlc, glycated hemoglobin; Met, metformin; T2DM, type 2 diabetes mellitus; VAl, visceral adiposity index; WC, waist circumference. immediately or stored at $-20^{\circ} \mathrm{C}$ for later use. The fasting serum glucose (FSG), triglyceride (TG), high-density lipoprotein cholesterol (HDL-c), urea and creatinine levels, and aspartate transaminase, alanine aminotransferase, and alkaline phosphatase activities were determined colorimetrically (Roche-Cobas C 311, Roche Diagnostics GmbH). Serum insulin level was determined by an immunoassay method (Roche-Cobas e 411, Roche Diagnostics GmbH).

\section{Visceral adiposity index (VAI)}

The VAI is an empirical mathematical model, which is gender specific and based on simple anthropometric (BMI and WC) and functional parameters (TG and HDL-c), is an indicator of body fat distribution and function. Calculation of VAI was according to the formula given by Amato et al. ${ }^{15}$ The formula is a linear equation derived by extrapolation from the relationship between BMI and WC in a healthy normal/overweight population. Distribution mode of adipose tissue was corrected for TG and HDL-c levels to determine the VAI as follows:

$$
\begin{aligned}
\text { Female VAI }= & (\mathrm{WC} / 36.58+(1.89 \times \mathrm{BMI})) \times(\mathrm{TG} / 0.81) \\
& \times(1.52 / \mathrm{HDL}) \\
\text { Male VAI }= & (\mathrm{WC} / 39.68+(1.88 \times \mathrm{BMI})) \times(\mathrm{TG} / 1.03) \\
& \times(1.31 / \mathrm{HDL}),
\end{aligned}
$$

where $\mathrm{WC}$ is expressed in $\mathrm{cm}, \mathrm{BMI}$ in $\mathrm{kg} / \mathrm{m}^{2}, \mathrm{TG}$ in $\mathrm{mmol} / \mathrm{L}$, and HDL in $\mathrm{mmol} / \mathrm{L}$. 


\section{Statistical analysis}

The data were statistically analyzed using GraphPad Prism 5.1 software (GraphPad Software Inc., La Jolla, CA, USA). Continuous variables were presented as mean \pm SD. Discrete variables were presented as numbers and frequencies. The chi-square test was used to determine the significance of association between discrete variables. Paired $t$-test was used to determine the difference between pretreatment and posttreatment values. Analysis of variance was used to determine the significance difference between means of independent samples and supported by Bonferroni's post hoc analysis at $P$-value $<0.05$.

\section{Results}

The baseline data for the T2DM patients are shown in Table 1. There were no significant differences $(P>0.05)$ in the parameters between groups. After 90 days of treatment, blood HbA1c levels of the GKB group $(7.7 \% \pm 1.2 \%)$ were significantly lower $(P<0.001)$ than baseline values $(8.6 \% \pm 1.6 \%$; Figure $2 \mathrm{~A})$, while in the placebo group $(8.4 \% \pm 2.1 \%)$, the decrease in $\mathrm{HbAlc}$ value from baseline $(8.8 \% \pm 2.3 \%)$ was not significant $(P>0.05)$. The
FSG levels were significantly lower $(154.7 \pm 36.1 \mathrm{mg} / \mathrm{dL}$; $P<0.001)$ than baseline values $(194.4 \pm 66.1 \mathrm{mg} / \mathrm{dL})$ after 90 days of treatment with GKB extract and Met, while the values for the placebo group $(173.8 \pm 68.3$ vs baseline $166.7 \pm 56.8 \mathrm{mg} / \mathrm{dL})$ were not significantly different $(P=0.53$; Figure 2B). Although treatment with GKB extract significantly decreased $(P=0.006)$ serum insulin levels after 90 days from $18.5 \pm 8.9 \mu \mathrm{U} / \mathrm{mL}$ at baseline to $13.4 \pm 7.8 \mu \mathrm{U} / \mathrm{mL}$, this change in value was also not significantly different $(P>0.05)$ from that of the placebo group at the end of treatment period. Similarly, the serum insulin levels in the placebo group did not change significantly $(P=0.32)$ after 90 days of GKB extract and Met treatment $(15.8 \pm 6.4 \mu \mathrm{U} / \mathrm{mL})$ from the baseline values (17.5 $\pm 8.1 \mu \mathrm{U} / \mathrm{mL}$; Figure $2 \mathrm{C}$ ). The pattern was similar for IR index (Figure 2D).

However, treatment with GKB extract and Met decreased the BMI of patients significantly $(P<0.001)$ from $34.0 \pm 6.0 \mathrm{~kg} / \mathrm{m}^{2}$ at baseline to $31.6 \pm 5.1 \mathrm{~kg} / \mathrm{m}^{2}$ after 90 days. The BMI of patients on placebo did not change after 90 days of treatment (Figure 3A). Moreover, GKBtreated patients showed significantly lower $(P<0.001) \mathrm{WC}$ after 90 days $(102.6 \pm 10.5 \mathrm{~cm})$ than baseline $\mathrm{WC}$ values

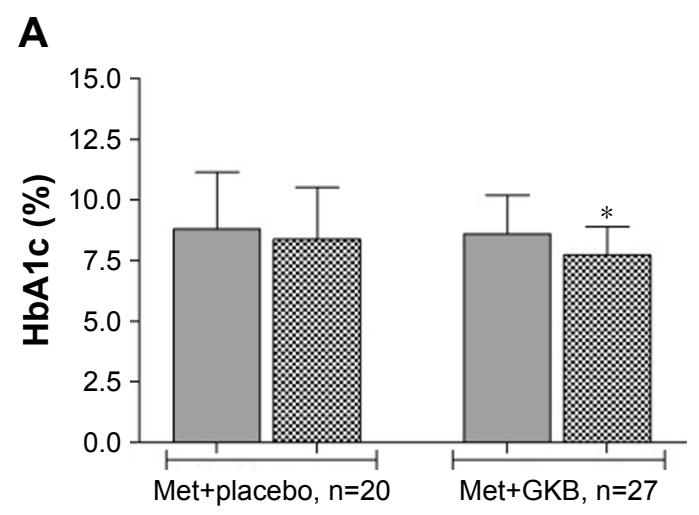

C

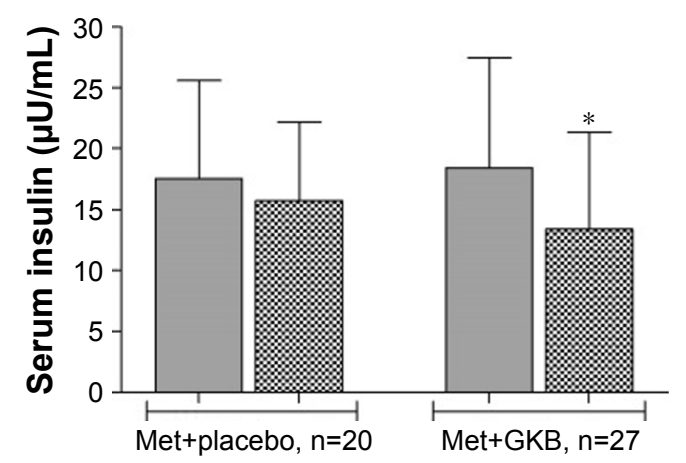

B

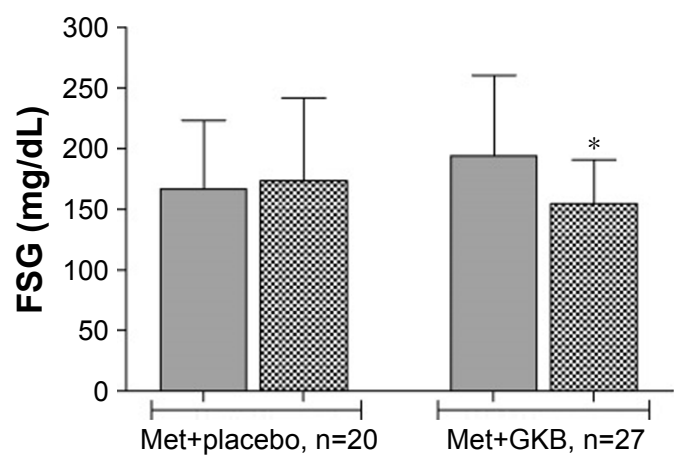

D

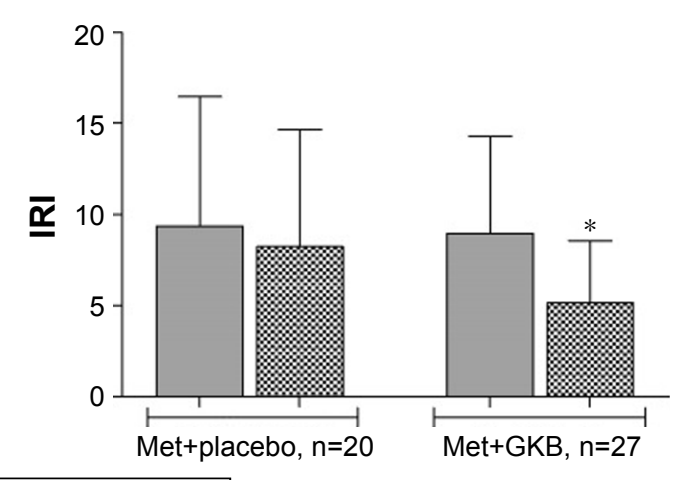

$\square$ Baseline $\quad$ After 90 days

Figure $2 \mathrm{HbAlc}$, FSG, serum insulin, and IRI of T2DM patients and treated with $120 \mathrm{mg}$ GKB extract/day for 90 days.

Notes: (A) HbAIc; (B) FSG; (C) serum insulin; and (D) IRI. Values are presented as mean \pm SD. *For each treatment group, mean is significantly different (P<0.05) from the baseline value.

Abbreviations: FSG, fasting serum glucose; GKB, Ginkgo biloba; HbAIc, glycated hemoglobin; IRI, insulin resistance index; Met, metformin; T2DM, type 2 diabetes mellitus. 
A

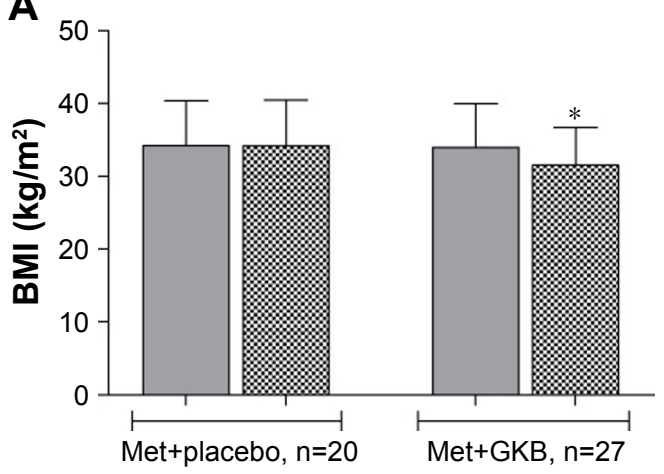

B

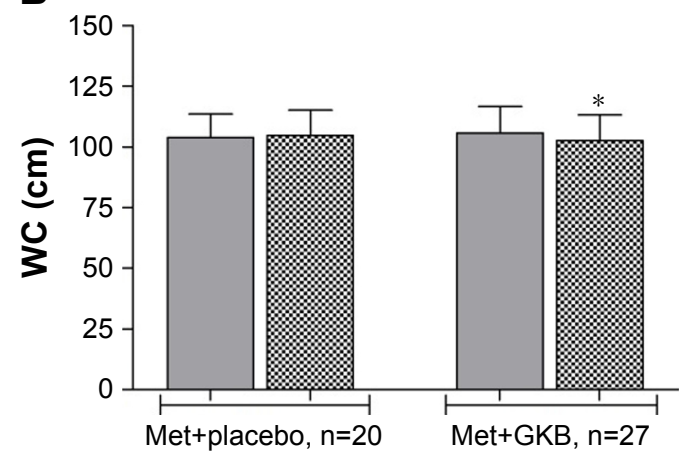

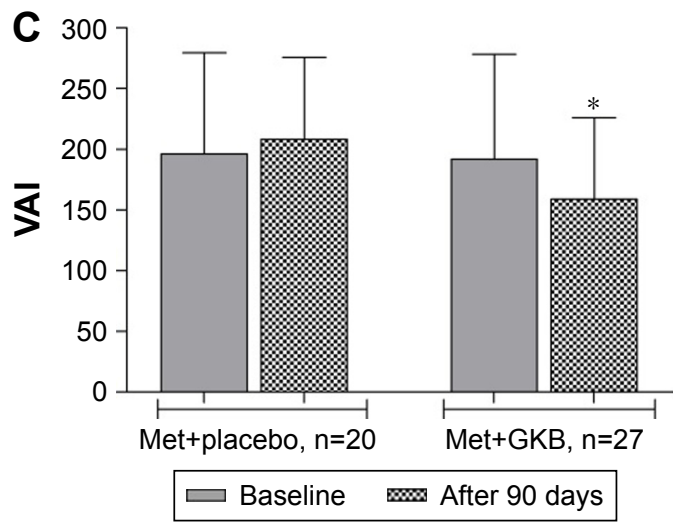

Figure $3 \mathrm{BMI}, \mathrm{WC}$, and VAl of T2DM patients and treated with $120 \mathrm{mg}$ GKB extract/day for 90 days.

Notes: (A) BMI; (B) WC; and (C) VAI. Values are presented as mean \pm SD. *For each treatment group, mean was significantly different $(P<0.05)$ from the baseline value. Abbreviations: BMI, body mass index; GKB, Ginkgo biloba; Met, metformin; T2DM, type 2 diabetes mellitus; VAl, visceral adiposity index; WC, waist circumference.

$(106.0 \pm 10.9 \mathrm{~cm})$. This parameter did not change in value significantly in patients treated with placebo plus Met (Figure 3B). The VAI significantly decreased $(P=0.007)$ after 90 days of treatment with GKB extract and Met to $158.9 \pm 67.2$ from the baseline value of $192.0 \pm 86.2$, while there was no significant change $(P=0.4)$ in the placebo group $(208.2 \pm 67.5$ vs baseline 196.5 \pm 82.8 ; Figure 3C).

Table 2 shows the effect of 90-day GKB extract and Met treatment on serum liver enzymes activities urea and creatinine concentrations. The treatment only significantly

Table 2 Serum biochemical parameters of T2DM patients maintained on Met and treated with GKB extract

\begin{tabular}{llllll}
\hline Parameters & \multicolumn{2}{l}{ Met+placebo, $\mathbf{n = 2 0}$} & & \multicolumn{2}{c}{ Met+GKB, $\mathbf{n}=\mathbf{2 7}$} \\
\cline { 2 - 3 } \cline { 5 - 6 } & Baseline & $\mathbf{9 0}$ days & & Baseline & $\mathbf{9 0}$ days \\
\hline AST (U/L) & $22.2 \pm 13.5$ & $18.1 \pm 5.4$ & & $18.4 \pm 6.6$ & $18.8 \pm 4.4$ \\
ALT (U/L) & $19.2 \pm 8.7$ & $17.0 \pm 7.3$ & & $17.8 \pm 8.9$ & $17.5 \pm 7.4$ \\
ALP (U/L) & $97.6 \pm 27.0$ & $82.1 \pm 22.8^{*}$ & & $93.8 \pm 20.6$ & $86.1 \pm 15.6^{*}$ \\
Urea (mg/dL) & $25.6 \pm 7.5$ & $27.1 \pm 10.6$ & & $28.1 \pm 6.3$ & $24.5 \pm 6.9^{*}$ \\
Creatinine (mg/dL) & $0.67 \pm 0.17$ & $0.73 \pm 0.14^{*}$ & & $0.69 \pm 0.17$ & $0.60 \pm 0.16^{*}$ \\
\hline
\end{tabular}

Notes: Values are presented as mean $\pm S D$. *For each treatment group, mean is significantly different from the baseline value (paired $t$-test, $P<0.05$ ).

Abbreviations: ALP, alkaline phosphatase; ALT, alanine aminotransferase; AST, aspartate aminotransferase; GKB, Ginkgo biloba; Met, metformin; T2DM, type 2 diabetes mellitus. decreased $(P<0.05)$ serum ALP activity. The effects of treatment on serum urea and creatinine concentrations were variable. Serum urea significantly decreased at 90 days of treatment in the GKB-treated patients $(P=0.006)$, while in the placebo group, there was a nonsignificant increase from baseline values. Although serum creatinine level was significantly $(P=0.02)$ decreased in patients treated with GKB extract and Met, it was only marginally lower after 90 days of treatment than baseline; meanwhile, for the placebo group, this value was significantly increased $(P=0.02)$.

There were significant increases $(P<0.05)$ in $\mathrm{Hb}$ concentration, hematocrit, and red blood cell count from the baseline values in GKB- and Met-treated patients after 90 days (Table 3). In diabetic patients, placebo treatment did not affect the values of these parameters. The white blood cell count did not change either in the GKB or in the placebo group after 90 days. However, the platelet count was significantly lower $(P<0.05)$ in diabetic patients after treatment with placebo and Met.

\section{Discussion}

T2DM patients are prone to various types of short- and longterm complications that may cause early death. ${ }^{16}$ The most 
Table 3 Hematological parameters of T2DM patients maintained on and treated with GKB extract

\begin{tabular}{|c|c|c|c|c|}
\hline \multirow[t]{2}{*}{ Parameters } & \multicolumn{2}{|c|}{$\begin{array}{l}\text { Met+placebo, } \\
n=20\end{array}$} & \multicolumn{2}{|c|}{$\begin{array}{l}\text { Met+GKB, } \\
n=27\end{array}$} \\
\hline & Baseline & 90 days & Baseline & 90 days \\
\hline $\mathrm{Hb}(\mathrm{g} / \mathrm{dL})$ & $12.9 \pm 1.5$ & $13.5 \pm 1.5$ & $12.6 \pm 1.9$ & $13.4 \pm 1.7 *$ \\
\hline Hct (\%) & $38.3 \pm 4.2$ & $40.9 \pm 8.2$ & $37.1 \pm 5.6$ & $41.0 \pm 5.2 *$ \\
\hline RBC $\left(\times 10^{9}\right.$ cells/L) & $4.6 \pm 0.5$ & $4.8 \pm 0.73$ & $4.8 \pm 0.61$ & $5.2 \pm 0.57 *$ \\
\hline WBC $\left(\times 10^{6}\right.$ cells/L) & $8.9 \pm 2.4$ & $8.5 \pm 1.9$ & $8.6 \pm 2.4$ & $8.1 \pm 2.6$ \\
\hline Platelet $\left(\times 10^{9}\right.$ cells/L) & $252 \pm 59$ & $206 \pm 5 I^{*}$ & $233 \pm 54$ & $242 \pm 64$ \\
\hline
\end{tabular}

Notes: Values are presented as mean \pm SD. *For each treatment group, mean is significantly different from the baseline value (paired $t$-test, $P<0.05$ ).

Abbreviations: GKB, Ginkgo biloba; Hb, hemoglobin; Hct, hematocrit; Met, metformin; RBC, red blood cell; T2DM, type 2 diabetes mellitus; WBC, white blood cell.

common cause of these complications is uncontrolled hyperglycemia, which results in abnormalities including vascular rigidity, nephropathy and retinopathy, and peripheral neuropathy. ${ }^{17}$

Met is widely used as the first-line drug of choice in T2DM patients. ${ }^{18}$ Global data, in 2010, showed that T2DM patients using Met alone accounted for $\sim 30 \%$ of all patients treated with oral antidiabetic agents. ${ }^{19}$ Met improves the glycemic control primarily through the suppression of release of glucose from the liver. ${ }^{20}$ However, long-term use of Met and its analogs may lead to various adverse effects including gastrointestinal-related symptoms and lactic acidosis. ${ }^{21,22}$

The current practice in T2DM treatment and glycemic control is far from satisfactory. ${ }^{23}$ It has been recommended that Met-based protocol should include various types of oral antidiabetic agents to achieve good glycemic control. ${ }^{18}$ The combination treatments are for the avoidance of inadequate response from the use of Met alone. It was shown in clinical trials that using Met with other antidiabetic agents is effective in improving blood HbA1c levels. ${ }^{21,22}$

Several natural compounds are used as a part of the treatment protocol for T2DM, and the outcomes are promising. ${ }^{24}$ However, to date, the efficacy of GKB extract to control hyperglycemia has not been determined. This study is the first 90-day, placebo-controlled trial designed to determine the effectiveness of GKB extract in the enhancement of glycemic control by Met in T2DM patients. This study included T2DM patients poorly managed with Met alone. To meet the enrollment criteria for the study, patients recruited were on fixed Met dose for at least 6 months, with their blood HbA1c being $\geq 7.5 \%$. The study showed that GKB extract treatment, as an add-on therapy, improves FSG, serum insulin, and blood HbA1c over baseline values. The extract did not show the same positive effect compared with placebo-treated diabetic patients. The study also showed that changes in FSG were consistent with changes in the blood $\mathrm{HbAlc}$ in both the GKB extract- and the placebo-treated groups, confirming that GKB extract is beneficial in glycemic control as an adjuvant to Met. Significant decreases in BMI, WC, and VAI were reported only in GKB extract-treated patients. No serious or clinically significant adverse effects were observed in these patients. It is suggested that several active constituents in the GKB extract, including the polyphenols, are responsible for the improvement of peripheral tissue sensitivity to insulin, while reducing or totally overcoming IR. ${ }^{19}$

Previous studies showed that GKB extract effectively decreased FSG levels, protected islet $\beta$-cell functions, and improved metabolic homeostasis in experimental animal models. ${ }^{10,25}$ The effects of GKB extract could be attributed to various mechanisms such as improvement of pancreatic $\beta$-cell functions and blood insulin level, reduction in IR, and enhancement of blood glucose transport to peripheral tissue. ${ }^{26,27}$ Other studies also suggested that GKB extract improved insulin sensitivity through the enhancement of transcription of insulin receptor substrate 2 and reduction of level of the negative regulators of insulin signaling pathway. ${ }^{28,29}$ We suggest that the effects of GKB extract on BMI, WC, and VAI may be associated with its stimulatory effect on lipolysis. ${ }^{30,31}$ In fact, a recent study in mice showed that GKB extract can inhibit adipogenesis and regulate lipid metabolism, with consequential reduction in body weight, food intake, and significant increase in serum HDL-c level. ${ }^{31}$ The extract is also capable of reducing visceral adiposity in diet-induced obese rats. ${ }^{28}$ In this study, although GKB extract treatment significantly improved glycemic control, because of the relatively short 90-day study period, the difference between the effect of GKB extract and placebo was marginal. It is possible that a 90-day study is too short for the extract to exert its full effect. However, the results suggest that GKB extract is promising for use in the control of weight gain and as an adjuvant for the treatment of obesity and T2DM in humans. ${ }^{32,33}$

\section{Limitations}

The major limitations of this study are the small sample size, relatively short duration, and lack of dose-response data for GKB extract as an adjuvant to the antidiabetic drug. Therefore, future studies are warranted to determine the long-term effect of GKB extract by following up a larger study population. 


\section{Conclusion}

GKB extract improved blood $\mathrm{HbA} 1 \mathrm{c}$ and FSG concentration, IR index, BMI, and VAI when used as an adjuvant in T2DM patients poorly managed by Met alone. This finding confirms the beneficial role of GKB extract as a dietary supplement in the treatment regimen for T2DM patients.

\section{Acknowledgments}

These data were extracted from the $\mathrm{PhD}$ thesis submitted by T Ahmed Aziz to the Department of Pharmacology, College of Medicine, University of Sulaimani. The authors appreciate the College of Medicine, University of Sulaimani for its support and for providing facilities to this project.

\section{Disclosure}

The authors report no conflicts of interest in this work.

\section{References}

1. Padberg I, Peter E, González-Maldonado S, et al. A new metabolomic signature in type-2 diabetes mellitus and its pathophysiology. PLoS One. 2014;9(1):e85082.

2. Chen Y, Zhou L, Xu Y, Shen H, Niu J. A study on the relationship between genetic and environmental factors of type 2 diabetes mellitus in humans. Zhonghua Yu Fang Yi Xue Za Zhi. 2002;36(3):191-194.

3. Prevention CfDC. Diabetes Report Card, 2014. Atlanta, GA, USA: Centers for Disease Control and Prevention, US Dept of Health and Human Services; 2015.

4. Krentz AJ, Bailey CJ. Oral antidiabetic agents. Drugs. 2005;65(3): 385-411.

5. Upadhyay J, Polyzos SA, Perakakis N, et al. Pharmacotherapy of type 2 diabetes: an update. Metabolism. 2017;78:13-42.

6. Hedrington MS, Davis SN. Discontinued drug therapies to treat diabetes in 2015. Expert Opin Investig Drugs. 2017;26(2):219-225.

7. Stein SA, Lamos EM, Davis SN. A review of the efficacy and safety of oral antidiabetic drugs. Expert Opin Drug Saf. 2013;12(2):153-175.

8. Habeck M. Diabetes Treatments Get Sweet Help from Nature. Nat Med. 2003;9(10):1228.

9. Rizvi SI, Matteucci E, Atukeren P. Traditional medicine in management of type 2 diabetes mellitus. J Diabetes Res. 2013;2013:580823.

10. Mohanta TK, Tamboli Y, Zubaidha PK. Phytochemical and medicinal importance of Ginkgo biloba L. Nat Prod Res. 2014;28(10):746-752.

11. Boghdady NEl. Antioxidant and antiapoptotic effects of proanthocyanidin and ginkgo biloba extract against doxorubicin-induced cardiac injury in rats. Cell Biochem Funct. 2013;31(4):344-351.

12. Zhao Q, Gao C, Cui Z. Ginkgolide A reduces inflammatory response in high-glucose-stimulated human umbilical vein endothelial cells through STAT3-mediated pathway. Int Immunopharmacol. 2015;25(2): 242-248.

13. Biesinger S, Michaels HA, Quadros AS, et al. A combination of isolated phytochemicals and botanical extracts lowers diastolic blood pressure in a randomized controlled trial of hypertensive subjects. Eur J Clin Nutr. 2016;70(1):10-16.

14. American Diabetes Association. Economic costs of diabetes in the US in 2012. Diabetes Care. 2013;36(4):1033-1046.
15. Amato MC, Giordano C, Galia M, et al. Visceral Adiposity Index: a reliable indicator of visceral fat function associated with cardiometabolic risk. Diabetes Care. 2010;33(4):920-922.

16. Azevedo M, Alla S. Diabetes in sub-saharan Africa: Kenya, Mali, Mozambique, Nigeria, South Africa and Zambia. Int J Diabetes Dev Ctries. 2008;28(4):101-108

17. Long AN, Dagogo-Jack S. Comorbidities of diabetes and hypertension: mechanisms and approach to target organ protection. J Clin Hypertens (Greenwich). 2011;13(4):244-251.

18. American Diabetes Association. Standards of medical care in diabetes2014. Diabetes Care. 2014;37(3):887-887.

19. Lian F, Tian J, Chen X, et al. The efficacy and safety of Chinese herbal medicine Jinlida as add-on medication in type 2 diabetes patients ineffectively managed by metformin monotherapy: a doubleblind, randomized, placebo-controlled, multicenter trial. PLoS One. 2015;10(6):e0130550

20. Kirpichnikov D, McFarlane SI, Sowers JR. Metformin: an update. Ann Intern Med. 2002;137(1):25-33.

21. DeFronzo RA, Hissa MN, Garber AJ, et al. The efficacy and safety of saxagliptin when added to metformin therapy in patients with inadequately controlled type 2 diabetes with metformin alone. Diabetes Care. 2009;32(9):1649-1655.

22. Fonseca V, Rosenstock J, Patwardhan R, Salzman A. Effect of metformin and rosiglitazone combination therapy in patients with type 2 diabetes mellitus: a randomized controlled trial. JAMA. 2000;283(13): 1695-1702.

23. Ji L-N, Lu J-M, Guo X-H, et al. Glycemic control among patients in China with type 2 diabetes mellitus receiving oral drugs or injectables. BMC Public Health. 2013;13(1):602.

24. Chang HY, Wallis M, Tiralongo E. Use of complementary and alternative medicine among people living with diabetes: literature review. J Adv Nurs. 2007;58(4):307-319.

25. Rhee K-J, Lee CG, Kim SW, Gim D-H, Kim H-C, Jung BD. Extract of Ginkgo Biloba ameliorates streptozotocin-induced type 1 diabetes mellitus and high-fat diet-induced type 2 diabetes mellitus in mice. Int J Med Sci. 2015;12(12):987-994.

26. Cheng D, Liang B, Li Y. Antihyperglycemic effect of Ginkgo biloba extract in streptozotocin-induced diabetes in rats. Biomed Res Int. 2012;2013:162724.

27. Kudolo GB. The effect of 3-month ingestion of Ginkgo biloba extract on pancreatic $\beta$-cell function in response to glucose loading in normal glucose tolerant individuals. J Clin Pharmacol. 2000;40(6):647-654.

28. Banin RM, Hirata BKS, Andrade IS, et al. Beneficial effects of Ginkgo biloba extract on insulin signaling cascade, dyslipidemia, and body adiposity of diet-induced obese rats. Braz J Med Biol Res. 2014;47(9): $780-788$.

29. Zhou L, Meng Q, Qian T, Yang Z. Ginkgo biloba extract enhances glucose tolerance in hyperinsulinism-induced hepatic cells. J Nat Med. 2011;65(1):50-56.

30. Dell'Agli M, Bosisio E. Biflavones of Ginkgo biloba stimulate lipolysis in 3T3-L1 adipocytes. Planta Med. 2002;68(1):76-79.

31. Kang H. Hypocholesterolemic effect of Ginkgo biloba seeds extract from high fat diet mice. Biomed Sci Lett. 2017;23(2):138-143.

32. Hirata BKS, de Souza Figueiredo J, Telles MM. Ginkgo biloba extract $(\mathrm{GbE})$ : promising therapeutic perspective to treat obesity and diabetes. Curr Res Diabetes Obes J. 2017;3(2):001-003.

33. Hussain SA. Silymarin as an adjunct to glibenclamide therapy improves long-term and postprandial glycemic control and body mass index in type 2 diabetes. J Med Food. 2007;10(3):543-547. 


\section{Publish your work in this journal}

Drug Design, Development and Therapy is an international, peerreviewed open-access journal that spans the spectrum of drug design and development through to clinical applications. Clinical outcomes, patient safety, and programs for the development and effective, safe, and sustained use of medicines are the features of the journal, which

has also been accepted for indexing on PubMed Central. The manuscript management system is completely online and includes a very quick and fair peer-review system, which is all easy to use. Visit http://www.dovepress.com/testimonials.php to read real quotes from published authors.

Submit your manuscript here: http://www.dovepress.com/drug-design-development-and-therapy-journal 